\begin{abstract}
Seasonal migration of commercial-size $(\geq 102 \mathrm{~mm}$ carapace width $[\mathrm{CW}])$, morphometrically mature (MM) snow crabs (Chionoecetes opilio) from the eastern Bering Sea was examined in relation to the summer distribution of mature females to identify spatiotemporal overlap of males and females and determine the likelihood of mating associations for specific reproductive stages. Depth variation associated with this migration was examined to determine whether seasonal migrations contribute to previously recognized spatial differences in distributions of commercial-size males caught in the winter fishery and in the $\mathrm{Na}$ tional Marine Fisheries Service sum-

\author{
Daniel G. Nichol (contact author) \\ David A. Somerton \\ Email address for contact author: dan.nichol@noaa.gov \\ Resource Assessment and Conservation Engineering Division \\ Alaska Fisheries Science Center \\ National Marine Fisheries Service, NOAA \\ 7600 Sand Point Way NE \\ Seattle, Washington 98115
} mer bottom trawl survey. Depth data from 33 data storage tags attached to commercial-size MM males during 2010 and 2011 indicated that most males moved inshore during spring-a movement that would allow them to mate with multiparous females but not with pubescent-primiparous females. Smaller tagged males (100-102 mm CW) underwent more extensive inshore migrations, and several of them traveled more than $100 \mathrm{~km}$ in one direction. Both tagging and distribution data indicated that most commercial-size MM males remained predominantly on the outer shelf throughout the year (despite some inshore movements during spring) and, therefore, these males did not contribute greatly to the spatial differences observed between winter and summer.

Manuscript submitted 13 November 2014. Manuscript accepted 15 May 2015.

Fish. Bull. 113:313-326 (2015)

Online publication date: 4 June 2015. doi: 10.7755/FB.113.3.7

The views and opinions expressed or implied in this article are those of the author (or authors) and do not necessarily reflect the position of the National Marine Fisheries Service, NOAA.

\title{
Seasonal migrations of morphometrically mature male snow crab (Chionoecetes opilio) in the eastern Bering Sea in relation to mating dynamics
}

\begin{abstract}
Migrations of snow crabs (Chionoecetes opilio) differ between sexes and among different size classes, resulting in distributions that are highly structured and complex (Ernst et al., 2005). In the eastern Bering Sea, these migrations depend partially on bottom temperature gradients (Ernst et al., 2005) and can vary annually depending on the extent of the "cold pool" (Kotwicki and Lauth, 2013), a near bottom layer of cold $\left(<2^{\circ} \mathrm{C}\right)$ water that forms across mid-depths $(50-100 \mathrm{~m})$ of the eastern Bering Sea shelf. On the basis of data from the eastern Bering Sea shelf collected during the National Marine Fisheries Service (NMFS) annual summer bottom-trawl survey, immature crabs of both sexes undertake down-slope ontogenetic migrations that are generally from the northeast to the southwest (Otto, 1998; Zheng et al., 2001; Ernst et al., 2005). Upon reaching full maturity, both sexes undergo a terminal molt in the spring, after which they are thought to continue to migrate into deeper water (Oresanz et al., 2004; Ernst et al., 2005; Parada et al., 2010). For commercial-size males, $\geq 102 \mathrm{~mm}$ in carapace width $(\mathrm{CW})$, this migration is assumed to culminate on the outer shelf (depths of 100-200 m), where

the winter commercial fishery is concentrated (Orensanz et al., 2004). Less is known about smaller terminally molted males, but they are assumed to reside inshore of the commercial-size males.

Male migrations likely differ before and after the terminal molt. Because the transformation from a small-clawed "adolescent" stage to a large-clawed morphometrically mature (MM) stage coincides with the terminal molt for males, these stages have been distinguished by using the relationship of carapace width $(\mathrm{CW})$ to chela height $(\mathrm{CH})$ (Comeau and Conan, 1992; Stevens et al., 1993; Rugolo et al. ${ }^{1}$; Tamone et al., 2007). Because members of a cohort can reach maturity over multiple ages, the size distribution of MM males overlaps that of adolescent males. Although adolescent males are sometimes capable of mating, MM males

\footnotetext{
${ }^{1}$ Rugolo, L., D. Pengilly, R. MacIntosh, and K. Gravel. 2005. Reproductive potential and life history of snow crabs in the eastern Bering Sea. In Bering Sea snow crab fishery restoration research: final comprehensive performance report. (D. Pengilly and S. E. Wright, eds.), p. 57-323. NOAA Cooperative Agreement NA17FW1274. Div. Commer. Fish. Alaska Dep. Fish Game, Juneau, AK.
} 
have a distinct competitive advantage in securing mates (Sainte-Marie et al., 1997).

Seasonal inshore migrations of post-terminal-molt MM male snow crabs, at least in waters of eastern Canada, have been attributed to mating behavior. These migrations are either targeted toward pubescentprimiparous females, those that will soon terminally molt and then brood their first clutch after mating, or toward multiparous females, those carrying clutches in subsequent years (Lovrich et al., 1995; Sainte-Marie et al., 2008). In the eastern Bering Sea, pubescent-primiparous females reside in shallower water and mate 1-3 months (February to March) earlier than multiparous females (Somerton, 1982; Ernst et al., 2005; Kruse et al., 2007). Peak spawning and subsequent mating among multiparous females in the eastern Bering Sea occur between March and April (Rugolo ${ }^{2}$ ), although a small percentage may be in a receptive condition until July (Somerton, 1981).

Whether commercial-size MM males in the eastern Bering Sea undergo a seasonal inshore migration for the purpose of mating is unknown. If multiparous females in the eastern Bering Sea are relatively sedentary, as they are in eastern Canada (Lovrich et al., 1995), an inshore migration by commercial-size MM males may be necessary for successful mating. Earlier and more extensive inshore migrations would certainly be required to mate with pubescent-primiparous females (Parada et al., 2010). Theoretically, there may not be a need to migrate toward and mate with multiparous females because these females can store sperm over multiple years (Sainte-Marie and Carrière, 1995). However, depending on the sex ratios of functionally mature crabs, ratios that can affect mate choice (Sainte Marie et al., 2008; e.g., the southern Tanner crab [C. bairdi], Webb and Bednarski, 2010), most multiparous females are presumed to mate annually if males are available. An exception to this assumption occurs among some females that reside in colder-water areas $\left(<1.5^{\circ} \mathrm{C}\right)$ of the eastern Bering Sea and that spawn biennially (Rugolo et al. ${ }^{1}$ ).

Compared with the ontogenetic migrations of juvenile snow crabs in the eastern Bering Sea, little is known about the seasonal migration patterns of MM males because of the paucity of sampling during times other than those of the NMFS summer bottom trawl survey and the winter commercial fishery. The offshore migration of recently terminally molted MM males in the eastern Bering Sea was demonstrated by a study of the Alaska Department of Fish and Game (ADFG), during which MM males were tagged with spaghetti tags during summer, on the middle shelf, and many were recaptured near the outer shelf during the following winter snow crab fishery (Gravel et al., 2006; Pengilly ${ }^{3}$. However, because the fishery and, therefore,

\footnotetext{
${ }^{2}$ Rugolo, L. 2014. Personal commun. Alaska Fish. Sci. Cent., Seattle, WA 98115.

${ }^{3}$ Pengilly, D. 2014. Personal commun. Alaska Dep. Fish Game, Kodiak, AK 99615.
}

recaptures occur only on the outer shelf, the fraction of MM males that migrate to the outer shelf is unknown, and nothing is known about the possibility of these males migrating back to the middle shelf. Furthermore, because of the reliance on the fishery for recaptures, ADFG tagged only commercial-size males, and information on migration and distribution for small MM males (70-100 $\mathrm{mm} \mathrm{CW}$ ), which are prevalent in the eastern Bering Sea (Otto, 1998) and potentially important contributors to breeding, is lacking.

For commercial-size MM males, fishery managers have recognized a seasonal change in distribution, which is centered on the middle shelf of the eastern Bering Sea (bottom depth: $<100 \mathrm{~m}$ ) during the summer (Foy and Armistead, 2013) but shifts to the outer shelf (bottom depth: 100-200 m) from January to March when and where the fishery typically occurs (Orensanz et al., 2004; Bowers et al., 2011; Turnock and Rugolo4). Part of this distributional shift may be explained by the post-terminal-molt migration from the middle to the outer shelf (Orensanz et al., 2004), but an inshore spring migration by outer shelf males may contribute to this shift as well. Such a migration was documented by Lovrich et al. (1995), who found that MM male snow crabs $<70 \mathrm{~mm} \mathrm{CW}$ in the Gulf of St. Lawrence migrated to shallow water during early spring to mate with pubescent-primiparous females. In that study, however, large MM males tended not to migrate as far inshore or as early in the year as males $<70 \mathrm{~mm} \mathrm{CW}$, therefore, limiting their mating to multiparous females.

Determining where and when large (>100 $\mathrm{mm} \mathrm{CW})$ and small (70-100 mm CW) MM males may migrate, and where they are spatially distributed in relation to pubescent-primiparous and multiparous females, can help elucidate which mating associations occur in the eastern Bering Sea. Although at least some large, recently terminally molted MM males migrate into deeper water after summer, it is not known whether these males seasonally migrate back inshore to mate with multiparous females or perhaps to shallower waters where pubescent-primiparous females reside (Parada et al., 2010). If seasonal inshore migrations do occur, it is not known how much they contribute to temporal differences in the spatial distribution of large MM males. For small MM males in the eastern Bering Sea, it is unclear what component of the mature female stock they associate with and mate with, because of the difficulty in recapturing small, tagged animals in the fishery and because the spatial distribution of these small MM males has not been examined separately from that of adolescents.

Using data storage tags (DSTs) that were capable of timed depth recordings and were deployed on com-

\footnotetext{
4 Turnock, B. J. and L. J. Rugolo. 2011. Stock assessment of eastern Bering Sea snow crab. In Stock assessment and fishery evaluation report for the king and Tanner crab fisheries of the Bering Sea and Aleutian Islands regions. 2011 crab SAFE, 37-168 p. North Pacific Fishery Management Council, Anchorage, AK [Available at website.]
} 
mercial-size MM male snow crab, we examined the seasonal inshore and offshore migrations of these males to determine if their migrations contribute to the reported differences between distribution of MM male snow crab during summer and their distribution during winter. Second, by examining the summer distribution of mature females, we attempted to infer the components of the female stock that are associated with and mate with large MM males. Finally, we compared the distribution of both large and small MM males with that of mature females to assess the potential for size-specific male-female mating associations.

\section{Materials and methods}

\section{Tagging}

A total of 277 morphometrically mature male snow crab (96-134 mm CW) were tagged and released with pressure-and-temperature-recording DSTs on 18-22 April $2010(n=120)$ and 7-8 March $2011(n=157)$, near the end of each fishing season to ensure that tagged crab were not recaptured until the following year. Tagging operations occurred on the winter snow crab fishing grounds northwest of the Pribilof Islands at approximately $57^{\circ} 35 \mathrm{~N}$ in 2010 and about $100 \mathrm{~km}$ farther north at $58^{\circ} 30 \mathrm{~N}$ in 2011 (Fig. 1). DSTs were attached to spaghetti tags that were wrapped around the carapace of the crab between the first and second walking legs. Because male snow crab do not molt after they reach maturity, the effect of tagging on their behavior and mortality was assumed to be negligible. In April 2010, an additional 221 snow crab were tagged and released with numbered spaghetti tags without an attached DST as a control to determine whether the additional DST attachment affected capture rate, as well as to help examine site fidelity.

Crabs were captured and tagged aboard commercial crab pot fishing vessels Kiska Sea (in 2010) and Pacific Sun (in 2011) during normal commercial fishing operations, and they were released within $10 \mathrm{~min}$ of capture at the same location. All tagged male crabs had large claws and had new to slightly worn hard shells, conditions that predominated in the catches during the time of tagging. Only crabs that possessed all their limbs were selected for tagging. Tagged crabs were recaptured by commercial crab pot vessels during the following winter and spring snow crab fisheries in 2011 and 2012, and a tag reward program was implemented to provide an incentive to return tags. Locations where crabs were recaptured were documented by the fishermen who returned tags.

The DSTs, Cefas G5 Long Life ${ }^{5}$ tags with 2 MB of memory (Cefas Technology Limited, Lowestoft, UK), measured depth (pressure) at 1-min intervals, with an

\footnotetext{
${ }^{5}$ Mention of trade names or commercial companies is for identification purposes only and does not imply endorsement by the National Marine Fisheries Service, NOAA.
}

accuracy of $\pm 2 \mathrm{~m}$ and precision of $<0.08 \mathrm{~m}$, and temperature at 30 -min intervals, with an accuracy of $\pm 0.1^{\circ} \mathrm{C}$ and precision of $0.03^{\circ} \mathrm{C}$. DSTs were bullet-shaped with dimensions of $8 \times 31 \mathrm{~mm}$ and weighed $1 \mathrm{~g}$ in water.

\section{Analyses of snow crab depth and ambient temperature}

The shelf of the eastern Bering Sea slopes down gradually from northeast to southwest from the Alaska mainland (i.e., north of $58^{\circ} \mathrm{N}$ ) out to the shelf break (bottom depth: approximately $200 \mathrm{~m}$ ); therefore, changes in tag depth were used as proxies or indicators of inshore and offshore movements (Fig. 1). Because migrations likely included movements parallel to bottom depth contours (i.e., movements in northwest and southeast directions), exact migration pathways could not be determined.

For each recaptured crab, the recorded tag depths were plotted against time (e.g., month) to determine whether seasonal inshore and offshore migrations were made and whether migrations were consistent among all individuals. Temperatures also were plotted against time to document the temperatures of areas inhabited by snow crabs in the eastern Bering Sea. In a few cases, tag temperatures were compared with temperatures collected during the NMFS summer bottom trawl survey, to corroborate the position of a crab from release and recapture positions and to indicate their proximity to the cold pool.

\section{Distribution of mature females}

The distributions of primiparous and multiparous females were plotted with data from the 2010 and 2011 NMFS summer bottom trawl surveys (Foy and Armistead, 2013; Lauth and Nichol, 2013) to examine the extent to which their distributions overlapped with tagged MM males and to infer whether the migration of large MM males would be necessary to create mating opportunities. A critical assumption for this comparison was that the mature (i.e., primiparous and multiparous) female distributions observed during the summer survey were representative of the mature female distributions during the preceding winter-spring mating period. Primiparous females were identified as those females with uneyed eggs, clutch sizes $1 / 8$ to $3 / 4$ full, and soft to clean hard shell conditions. Multiparous females were identified as those females with either uneyed or eyed eggs, full clutch sizes, and hard shells with scratches or wear.

\section{Distribution of morphometrically mature males}

Broad-scale geographic distributions of MM male snow crabs during summertime were analyzed with data collected annually (1989-2011) during the NMFS summer bottom trawl survey (Foy and Armistead, 2013; Lauth and Nichol, 2013), where stations were fixed and positioned $37 \mathrm{~km}$ apart from each other. Distributions were plotted for 4 male categories; that is, for 2 different size classes $(70-100 \mathrm{~mm} \mathrm{CW}$ and $>100 \mathrm{~mm} \mathrm{CW})$, each 


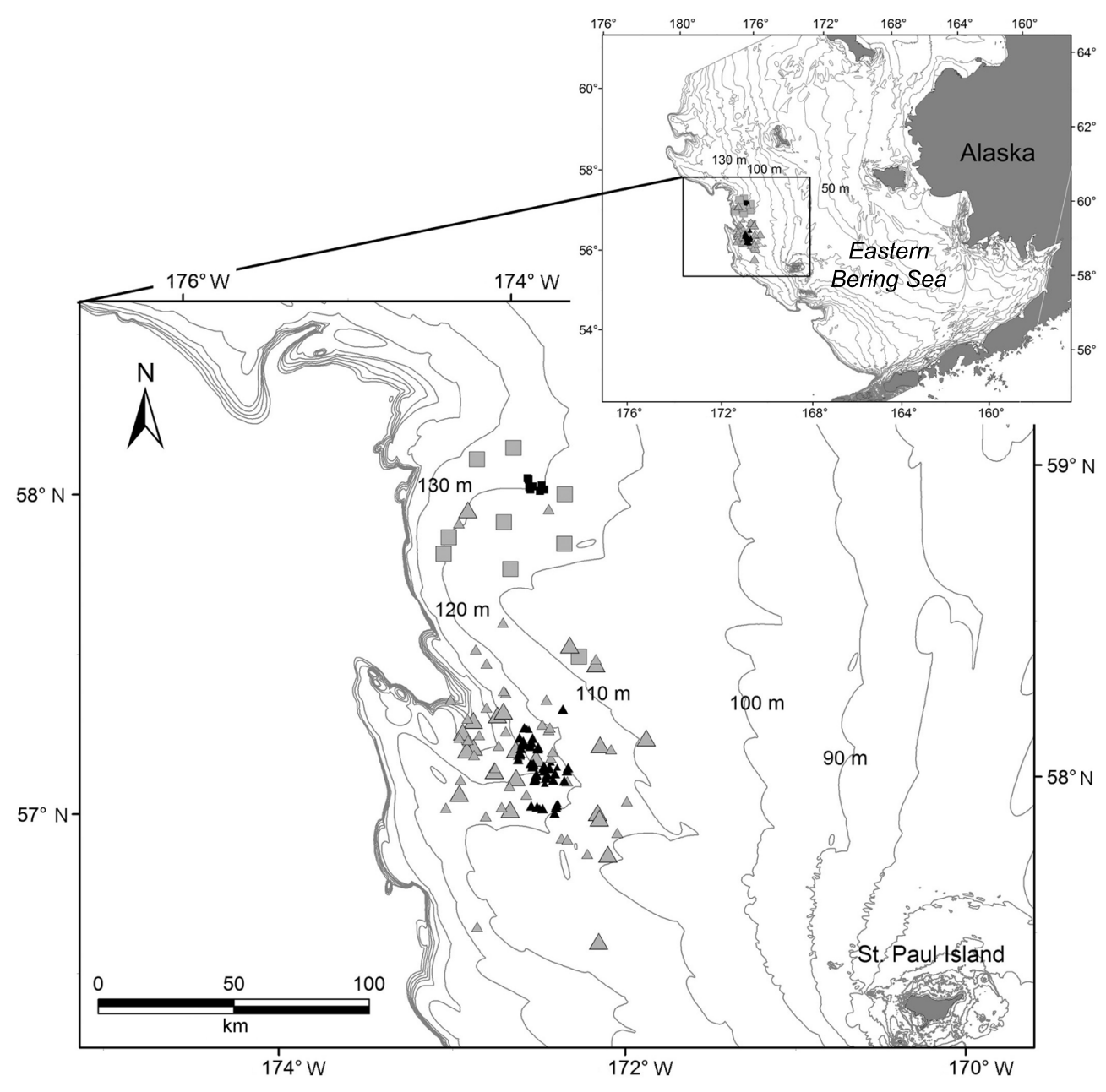

Figure 1

Release and recapture locations of morphometrically mature male snow crabs (Chionoecetes opilio) tagged with data storage tags (DSTs) during 2010 and 2011 in the eastern Bering Sea, northwest of the Pribilof Islands, which include St. Paul Island. Small black triangles indicate releases in 2010 of crabs with DSTs and spaghettionly tags. Large and small gray triangles indicate recaptures of DSTs and spaghetti tags, respectively, from crabs released in 2010. Small black squares indicate releases in 2011 of crabs with DSTs. Large gray squares indicate recaptures of DSTs from crabs released in 2011. Lines with numbers indicate contours of bottom depths.

with 2 post-terminal-molt age categories representing MM males that recently terminally molted (in the current year; having a new shell) or in previous years (having an older shell). The new- and older-shell categories correspond to the shell conditions $\leq 2$ and $\geq 3$, respectively, as defined in Foy and Armistead (2013). MM males were distinguished from adolescent males by using a linear regression function relating $\ln (\mathrm{CH})$ to $\ln (\mathrm{CW})$ as calculated in Rugolo et al. ${ }^{1}$, where for each measured specimen $s$, MM status was assigned where

$$
C H_{\mathrm{s}}>e^{1.2899 \times \ln \left(C W_{\mathrm{s}}\right)-2.8628} \text {. }
$$

Because crabs measured for $\mathrm{CH}$ were subsampled from the catch at each station, their numbers were extrapolated to the entire catch at each station. Also, because males subsampled for $\mathrm{CH}$ were too few in number (mean: 24/station/year) to examine geographic distributions on an annual basis, data were pooled across years (1989-2011) for each station in the survey. For each survey station $i$, the relative proportion of MM males (PROP) was calculated with the following equation:

$$
P R O P_{\mathrm{i}}=\frac{\Sigma_{\mathrm{j}} N_{\mathrm{ij}}}{\Sigma_{\mathrm{ij}} N_{\mathrm{ij}}},
$$

where $\mathrm{N}_{\mathrm{ij}}=$ the extrapolated number of MM males at station $i$ during year $j$.

If $\mathrm{CHs}$ were not measured within a particular year and station, each missing value of $\mathrm{N}_{\mathrm{ij}}$ was estimated as the 

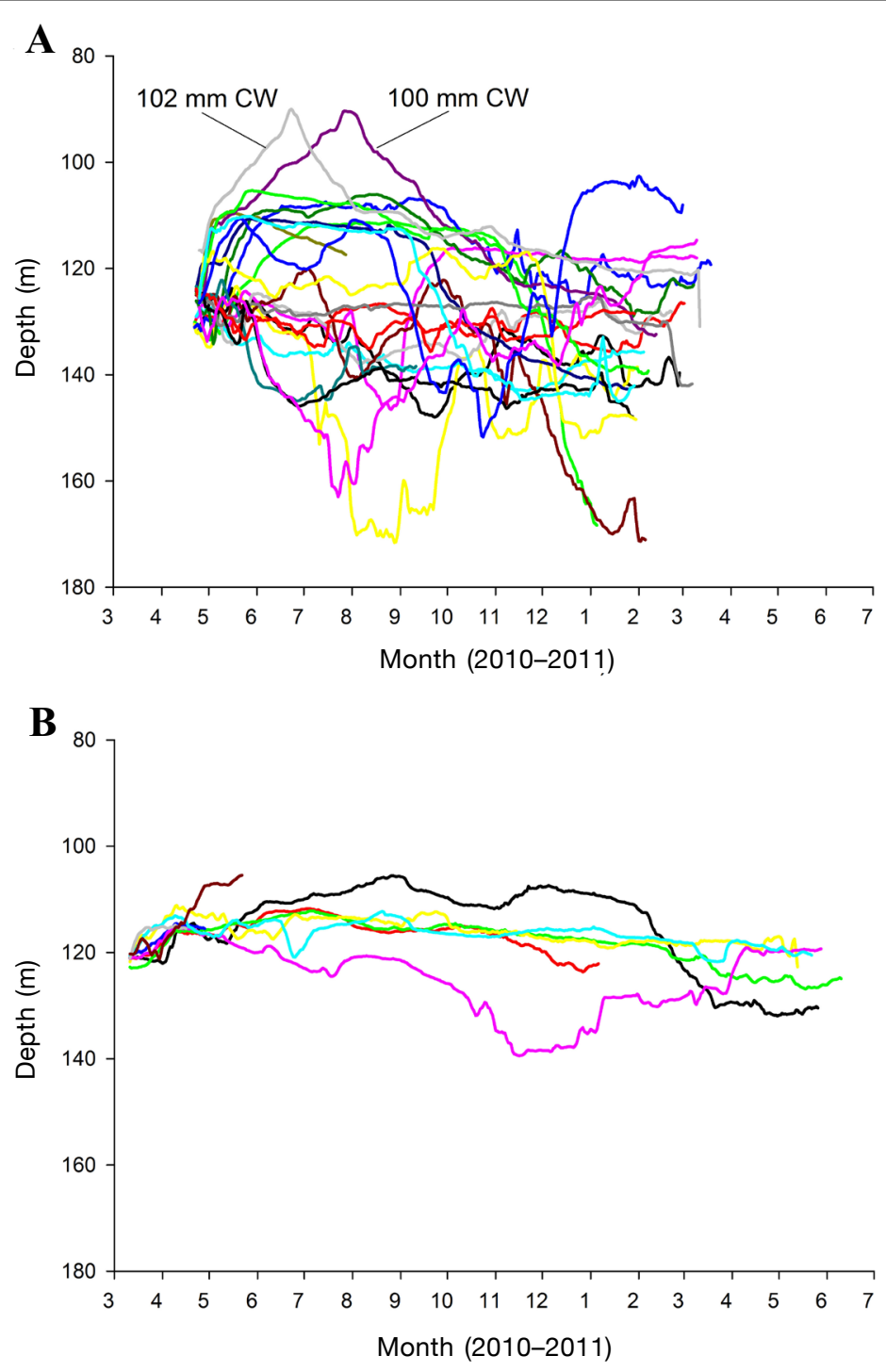

Figure 2

Timed depth recordings from data storage tags attached to morphometrically mature male snow crabs (Chionoecetes opilio) released the smallest tagged males (100 and $102 \mathrm{~mm}$ in carapace width) are indicated in panel A. in the eastern Bering Sea during (A) 2010 and (B) 2011. Two of

tion. Distributions were plotted as described previously for the size classes of 70-100 mm $\mathrm{CW}$ and $>100 \mathrm{~mm} \mathrm{CW}$ by using the data pooled across 1989-2011 and by using calculated relative proportions at each station.

\section{Results}

\section{Time at liberty and recapture locations}

A total of 33 male snow crabs with DSTs were recaptured, of which 4 individuals were 100-102 $\mathrm{mm} \mathrm{CW}$ and the rest ranged in size from 106 to $126 \mathrm{~mm} \mathrm{CW}$. In addition, 43 males with only spaghetti tags (not DSTs) were recaptured with sizes ranging from 101 to $130 \mathrm{~mm} \mathrm{CW} \mathrm{(Fig.} \mathrm{1).}$

Among males tagged with DSTs in 2010, 22 were recaptured in 2011 after 280-333 days at liberty and 1 was recaptured in 2012 after 640 days at liberty. Of the males released in 2011 with DSTs, 9 were recaptured in 2012 after 439-458 days at liberty. Among males tagged with spaghetti tags in 2010, 42 were at liberty between 274 and 319 days before recapture, and 1 other male was recaptured after 777 days. Recapture rates for snow crabs released in 2010 (and recaptured in 2011) were $18.3 \%$ ( $n=22)$ for those tagged with DSTs and $19.0 \%(n=42)$ for those tagged only with spaghetti tags, indicating essentially no difference in recapture rates between the 2 tag types. The attachment of the DSTs to spaghetti tags, therefore, was assumed to have no added effect on crab behavior or survival. Compared with males tagged in 2010 , those males tagged in 2011 were recaptured later in the year (May-June, in 2012) and at a lower rate $(5.7 \% ; n=9)$, owing to ice conditions that limited access to the fishing area during winter and caused the fishing season to be extended (Gutierrez, 2012). Recapture locations of both types of tags indicate some site fidelity, as indicated by the low degree of area overlap between crabs recaptured in 2011 and 2012 and released approximately

mean $\mathrm{N}_{\mathrm{i}}$ during years when sampling occurred. Algebraically, this mean is expressed as

$$
N_{\mathrm{i}}=\frac{\Sigma_{\mathrm{ij}} N_{\mathrm{i}}}{n_{\mathrm{i}}},
$$

where $n_{\mathrm{i}}=$ the number of years in which CHs were measured at station $i$.

\section{Distribution of adolescent males}

Adolescent males were also identified as above with the $\mathrm{CH}-\mathrm{CW}$ regression provided in the previous sec-
$100 \mathrm{~km}$ apart (Fig. 1).

\section{Occurrence and extent of inshore-offshore migrations}

Individual depth trajectories among tagged males were highly variable within the depth range they inhabited (90-172 $\mathrm{m}$ ), indicating a wide variety of individual migration routes (Fig. 2, A and B). For the crabs released in 2010, 3 general movement patterns were observed: 1) extensive upslope (i.e., inshore) movements, or changes in depth, $>20 \mathrm{~m}$ to depths $<120 \mathrm{~m}$ within 1 month after tagging; 2) very limited upslope or 


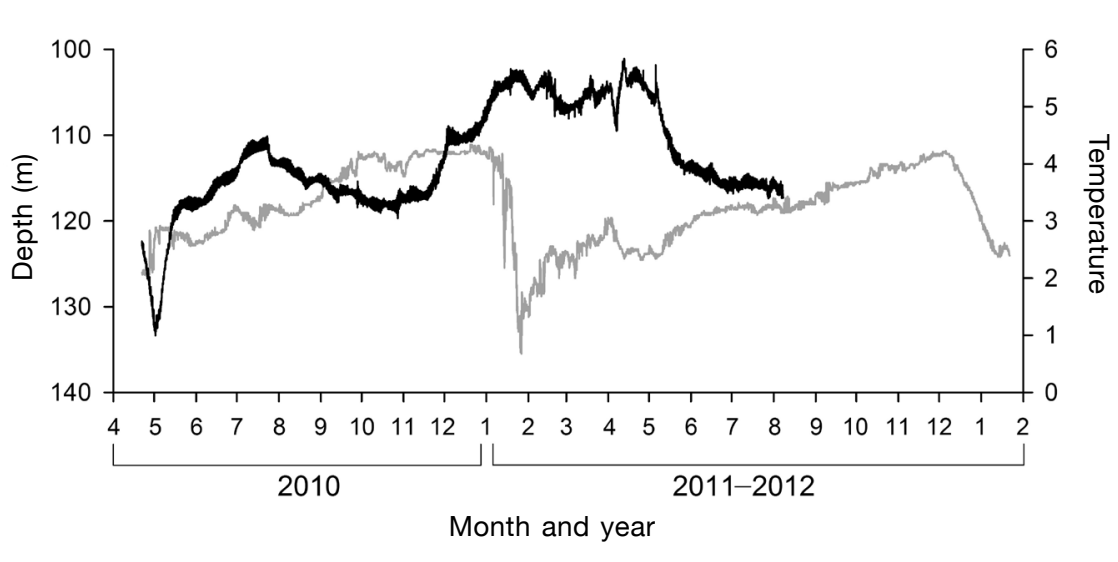

Figure 3

Timed depth (black line) and temperature (gray line) recordings from a data storage tag attached to a $100-\mathrm{mm}$ (carapace width) morphometrically mature male snow crab (Chionoecetes opilio) released in the eastern Bering Sea in 2010. This crab was at liberty for 640 days, although the depth sensor ceased to function approximately 5 months before its recapture.

males that were released at the more northern location in 2011 $(n=9)$ experienced temperatures about $1^{\circ} \mathrm{C}$ colder (mean: $2.3^{\circ} \mathrm{C}$ ) than the temperatures experienced by males $(n=24)$ released farther south in 2010 (mean: $3.3^{\circ} \mathrm{C}$ ). Seasonally, tagged males encountered the warmest temperatures during winter ( $\sim$ November-January) and the coldest temperatures during spring ( February-June). Annual differences in ambient temperature were apparent from DST data obtained from 2011 released males that were at liberty for more than 14 months (Fig. 4B); spring temperatures averaged $2.3^{\circ} \mathrm{C}$ in 2011 compared with $1.3^{\circ} \mathrm{C}$ in 2012. The coldest temperatures $\left(<1^{\circ} \mathrm{C}\right)$ were encountered by the 2 males that, in 2010, migrated farthest inshore to a depth of 90 m (Fig. 4A), where, on the basis

downslope movements (depth changes $<10 \mathrm{~m}$ ), remaining in depths $>120 \mathrm{~m}$; and 3) initial downslope movements of more than $20 \mathrm{~m}$ followed by extensive upslope movements, remaining in depths $>120 \mathrm{~m}$ (Fig. 2A). For crabs released in 2011 (north of 2010 releases), all 9 of the males that were recovered moved upslope immediately after release in the spring, but their depth changes were less extensive than those of tagged males released in 2010 (Fig. 2B), with changes ranging from 7 to $16 \mathrm{~m}$ (mean: $10.5 \mathrm{~m}$ ). Of the 5 males that were still at liberty during the following spring, in 2012, only 1 appeared to move upslope during the second spring.

Two of the 4 small tagged males (100-102 mm CW) undertook relatively long inshore migrations of $\sim 100$ $\mathrm{km}$, in depths ranging from 120 to $90 \mathrm{~m}$ (Fig. 1) during the spring and summer followed by an offshore migration during fall and winter. They did not migrate together because the timing of their inshore and offshore movements was offset by about 1 month (Fig. 2A). A third small individual (100 $\mathrm{mm} \mathrm{CW}$ ), released in 2010 and at liberty 640 days, undertook inshore and offshore migrations in both 2010 and 2011, but it did so during different months and to differing extents (Fig. 3). During successive spring periods, it resided at different depths (by approximately $20 \mathrm{~m}$ ) and different locations (separated by a distance of approximately $50 \mathrm{~km}$ ), indicating that individuals can undergo variable migrations from year to year. The fourth small male $(100 \mathrm{~mm}$ $\mathrm{CW}$ ), released in 2011, migrated inshore but not to the extent of the other 3 small tagged male snow crabs.

\section{Temperatures encountered}

Temperatures encountered by the tagged males ranged from $-0.5^{\circ} \mathrm{C}$ to $4.5^{\circ} \mathrm{C}$ (Fig. $4, \mathrm{~A}$ and $\mathrm{B}$ ), although those of the spatial distribution of bottom temperatures of the eastern Bering Sea shelf measured during the summer bottom trawl survey (Lauth, 2011), each of them migrated to the edge of the cold pool before initiating a return offshore migration. Both crabs remained at these colder temperatures for approximately 1 month before migrating offshore.

\section{Proximity of mature females to tagged males}

On the basis of the 2010, 2011, and 2012 data of the summer distributions of mature females, multiparous females were in close proximity $(<10 \mathrm{~km})$ to the locations where tagged males were released (Fig. 5, B, D, and $\mathrm{F}$ ). In addition, the inshore migrations of tagged males during spring (Fig. 2) indicated that there was a broad overlap with multiparous females at the time of multiparous mating (March-April). The increase in the abundance of multiparous females in the vicinity of the tag release areas from 2010 to 2011 indicates that more females were available to tagged males for breeding in 2011 than in 2010. In contrast, primiparous females were found much farther east (by distances $>50 \mathrm{~km}$ ) of the tagged males during all 3 years (Fig. 5, A, C, and E).

\section{Bathymetric overlap of tagged males and mature females}

The extent of cross-shelf inshore migrations by tagged males, defined here as the minimum depth reached during their time at liberty, increased (e.g., decreasing minimum depth) with decreasing crab size (Fig. 6; linear regression: $n=33$, coefficient of determination $\left[r^{2}\right]=0.39$, $P<0.001)$. Considering the depths where multiparous females were found during the NMFS summer bottom trawl surveys (Fig. 5), all tagged males occupied ar- 
eas where these females resided, including 9 of the large males ( $>113 \mathrm{~mm} \mathrm{CW}$ ) that remained at depths $>120 \mathrm{~m}$ and did not make a dedicated inshore migration. Therefore, they all had an opportunity to mate with multiparous females. In contrast, opportunities to mate with pubescent-primiparous females were unlikely given that these females were concentrated (Fig. 5) much farther to the east (shallower waters) and to the north. The two small tagged males that migrated to a 90-m depth were the exception; however, the months during which these males resided at a depth of $90 \mathrm{~m}$ (June-July), were well past the period of pubescent-primiparous mating (February-March).

\section{Summer distributions of morphometrically mature and adolescent males}

Small MM males (70-100 mm CW) were concentrated farther north and east (shallower water) of areas where large MM males (>100 $\mathrm{mm} \mathrm{CW}$ ) of the same shell condition resided, and new-shell MM males were concentrated farther east (shallower) than that where older-shell MM males of the same size class resided (Fig. 7, A-D). Large oldershell MM males were primarily distributed over the outer shelf (depths of 100-200 m), whereas new-shell MM males, from both size classes, were primarily distributed over the middle shelf (depths of 50-100 m), at least south of $59^{\circ} \mathrm{N}$. Adolescent males of both size classes were distributed over the middle shelf (i.e., south of $59^{\circ} \mathrm{N}$ ), and small individuals were distributed more to the northeast of areas where large individuals were distributed (Fig. 7, E and F).

\section{Discussion}

Most of the tagged MM males migrated inshore either shortly after their release during spring or during the following winter or spring. These migrations were not extensive enough to have contributed to the spatial difference in distributions between large males observed on the middle shelf during the NMFS summer bottom trawl survey and those males targeted on the outer shelf during the winter fishery. A seasonal shift in distribution of large males would be expected because of the fall migration of recently terminally molted males to deeper water, but this shift should be more prominent if these and oldershell MM males migrate back inshore every spring. Although springtime inshore migrations did occur, all but 2 of the tagged males remained on the outer shelf (depths $>100 \mathrm{~m}$ ) throughout their time at liberty.
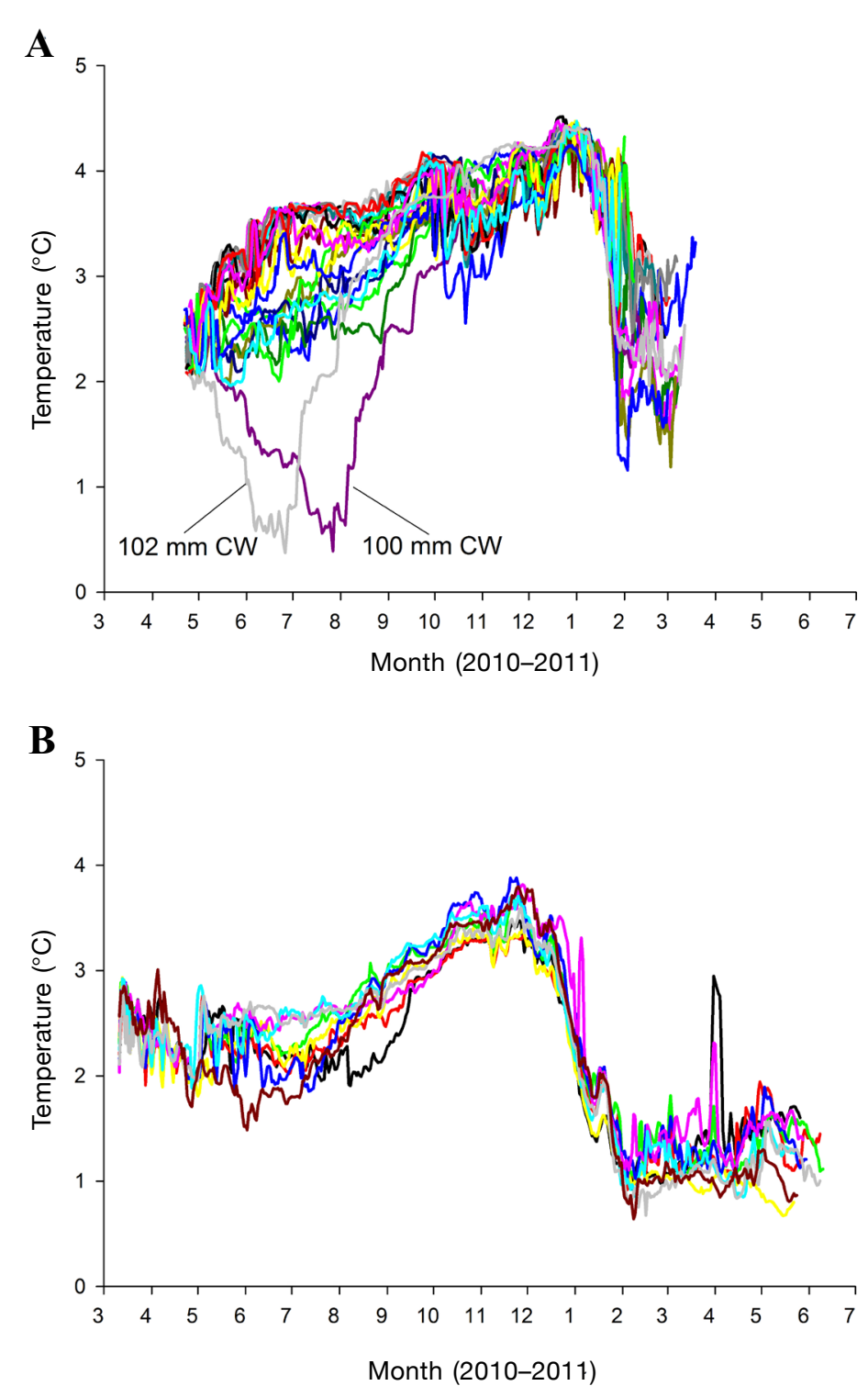

Figure 4

Mean daily temperature recordings from data storage tags attached to morphometrically mature male snow crabs (Chionoecetes opilio) released in the eastern Bering Sea during (A) 2010 and (B) 2011. Two of the smallest tagged males (100 and $102 \mathrm{~mm}$ in carapace width) are indicated in panel A.
The summer distribution of large, older-shell MM males (Fig. 7D) in waters deeper than $100 \mathrm{~m}$ confirmed the supposition that few of these individuals migrated back inshore to the middle shelf. The highest concentrations of large males found over the middle shelf (depths 50-100 m) during the summer survey (Orensanz et al., 2004; Turnock and Rugolo ${ }^{4}$, therefore, likely were not composed of MM males that seasonally migrated inshore but of recently terminally molted MM males that had yet to migrate 
A

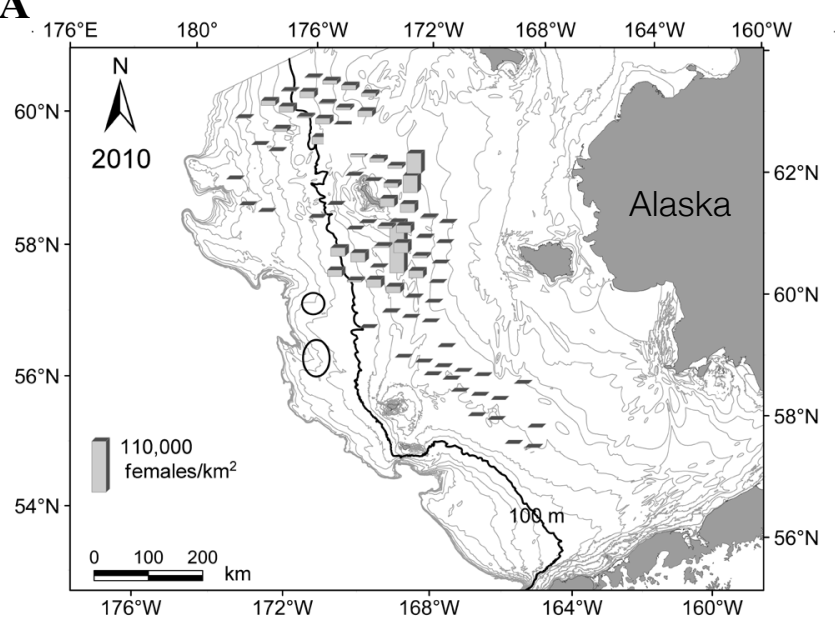

C

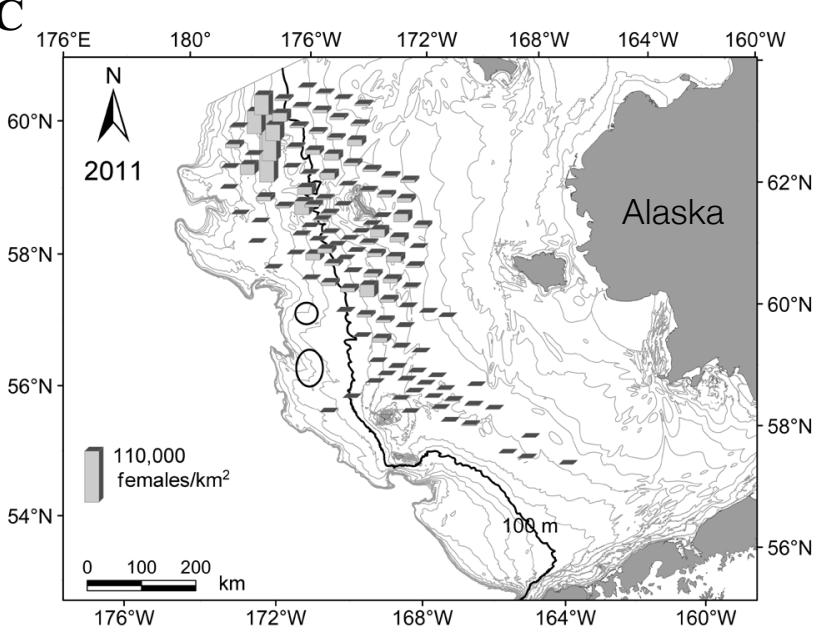

$\mathbf{E}$

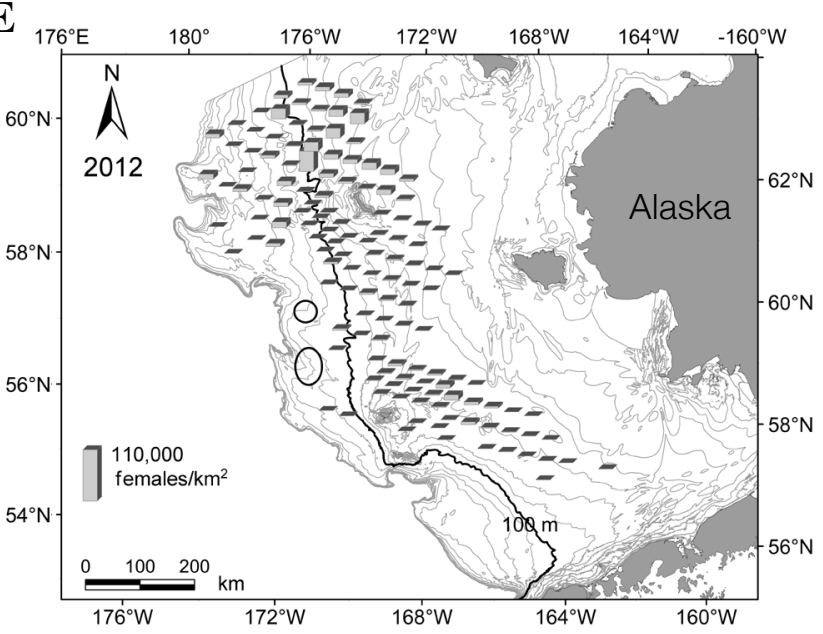

B

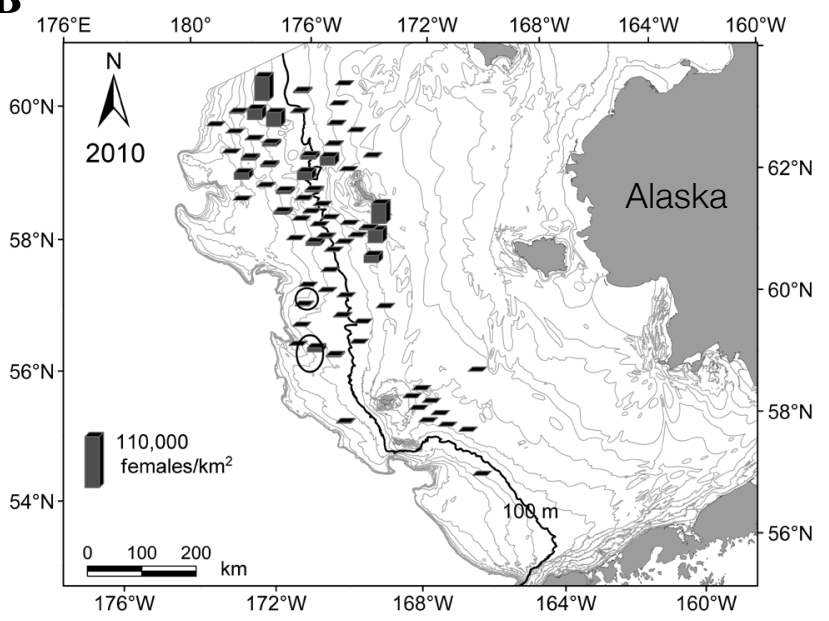

D

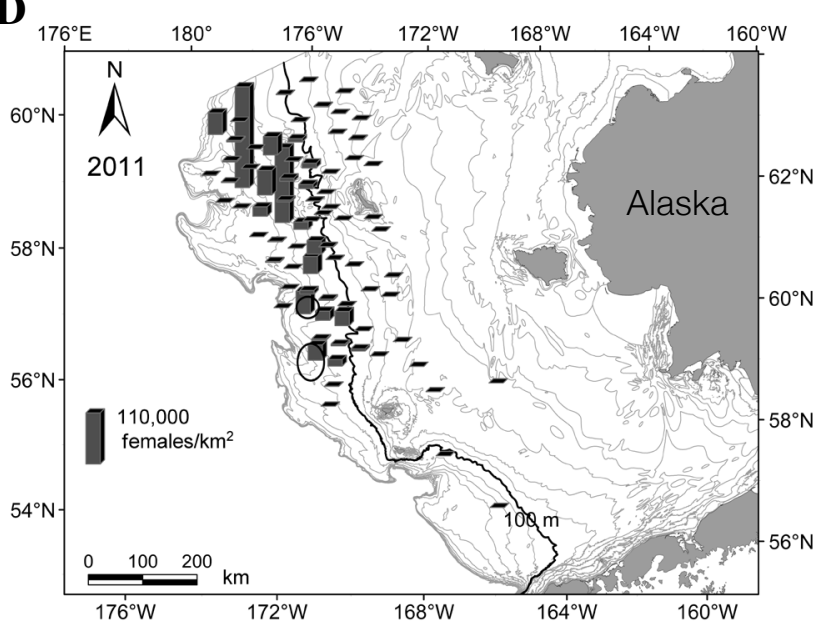

F

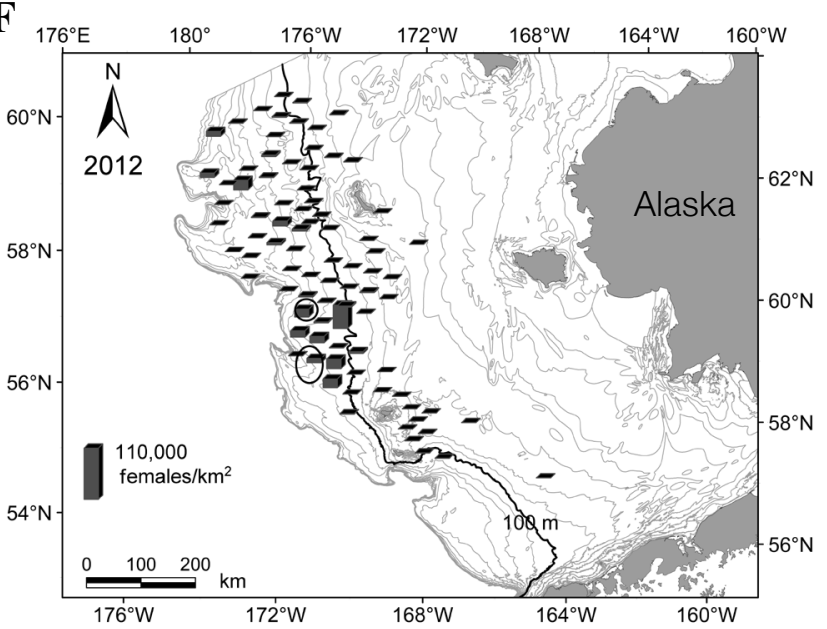

Figure 5

Summer distributions of primiparous female snow crabs (Chionoecetes opilio) during (A) 2010, (C) 2011, and (E) 2012 and of multiparous females during (B) 2010, (D) 2011, and (F) 2012, determined from data collected from the National Marine Fisheries Service summer bottom trawl surveys of the eastern Bering Sea. Bar heights indicate the catch per unit of effort (number of females per square kilometer). Ellipses indicate the tag release locations of morphometrically mature males. The black line indicates the $100-\mathrm{m}$ bottom-depth contour, designating the approximate border between the middle and outer shelves. 
offshore (Fig. 7B), as well as adolescent (small-clawed) males (Fig. 7F).

Regardless of the extent of inshore migrations among tagged MM males, most males traversed depths at which multiparous females resided, therefore, creating the potential for multiparous mating. Assuming that observed multiparous summer distributions do not differ significantly from their distributions during spring, when most of the multiparous mating occurs $\left(\right.$ Rugolo $\left.^{2}\right)$, we conclude that there was broad spatial overlap between large MM males and multiparous females over the outer shelf during the mating period. In contrast, it is highly unlikely that pubescent-primiparous females mated with large older-shell MM males because of the lack of spatial overlap. Even for the 2 small tagged males that migrated to a depth of $90 \mathrm{~m}$, a cross-shelf distance of approximately $100 \mathrm{~km}$, the period when they occupied the shallowest waters occurred well after pubescent-primiparous mating (February-March; Ernst et al., 2005).

The reasons why 2 of the small tagged males migrated such long distances are debatable, particularly if a reason is related to mating because these males reached their shallowest water depth during June and July when multiparous mating is almost over. Still, an argument can be made that, because some multiparous females were still in a receptive condition during June and July (Chilton et al., 2011), the small tagged MM males underwent more extensive inshore migrations to breed with these females and avoid competition from large MM males. The exclusion of small MM males by large MM males during mating has been observed for snow crabs in waters of eastern Canada (Moriyasu and Comeau, 1996; Sainte-Marie et al., 1997; Comeau et al., 1998) as well as for southern Tanner crabs in the laboratory (Paul et al., 1995). Lovrich et al. (1995) documented the inshore movement of 60-68-mm-CW MM male snow crabs from the Gulf of St. Lawrence, and they interpreted this movement as a migration of these males early in the season (December) in order that they could mate with pubescentprimiparous females when there was no competition from large MM males. They also reported that some intermediate-size ( $85 \mathrm{~mm} \mathrm{CW}) \mathrm{MM}$ males migrated inshore later in the season (May), the presumption being that they would mate with multiparous females while benefiting from reduced competition. As reported here, Lovrich et al. (1995) found that large MM males underwent some inshore movement during spring, but generally remained in deeper waters to mate with multiparous females.

A potential extension to this argument is that the 2 small tagged males engaged in grasping and carry- ing behavior (i.e., precopulatory embrace) and carried multiparous females from the main multiparous mating area to shallower waters, again, to reduce mating competition from larger MM males. Paired springtime migrations reportedly occur among snow crabs in Bonne Bay, Newfoundland, where MM males carry multiparous females from deeper to shallower waters (i.e., over a depth range from 150 to $10 \mathrm{~m}$ ) for mating (Taylor et al., 1985; Hooper, 1986; Ennis et al., 1990; Comeau et al., 1991). In these studies, the peak of inshore multiparous spawning and mating occurred later in the season than the multiparous spawning and mating that occurred in deeper waters (Ennis et al., 1990), perhaps lending support to the idea of late inshore multiparous spawning and mating in the eastern Bering Sea.

That the 2 small tagged males in this study were among the earliest to migrate inshore (i.e., to make a 20-m depth change) during the first month after release in April, followed by more gradual inshore movement into June and July (Fig. 2A), could be interpreted as males initially migrating earlier than the other males to pick among the receptive multiparous females, and as males subsequently migrating slower with a female in grasp. Such a scenario, however, is still hypothetical considering the long distances $(>100 \mathrm{~km})$ migrated and that the interpreted periods of grasping and carrying ( $>2$ months) are longer than those reported in the literature (Sainte-Marie et al., 2008). 

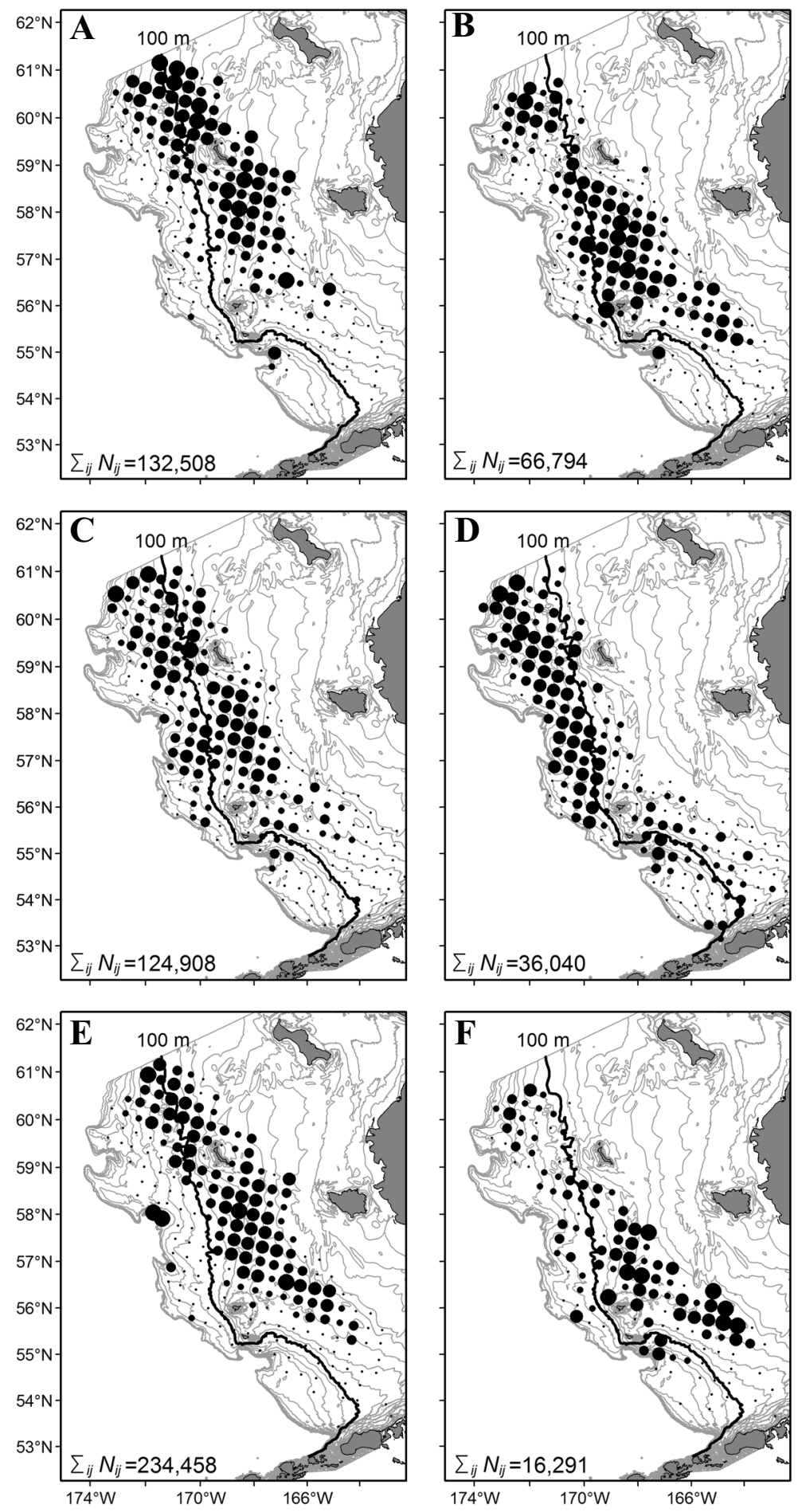

Figure 7

Distributions of morphometrically mature (MM; large-clawed) and adolescent (small-clawed) male snow crabs (Chionoecetes opilio) in the eastern Bering Sea during July, based on data collected annually (and pooled across years; 1989-2011) during National Marine Fisheries Service summer bottom trawl surveys. Distributions are classified within 4 categories of males: (A) small (70-100 mm in carapace width $[\mathrm{CW}]$ ) males with new-shell condition (B) large (>100 mm CW) males with new-shell condition, (C) small males with older-shell condition, and (D) large males with older-shell condition. Distributions
Assuming, on the basis of the data from DSTs, that large commercial-size MM males do not migrate inshore far enough, or soon enough, to mate with pubescent-primiparous females, the most likely partners for pubescent-primiparous mating were small (70-100 mm CW) MM males. Adolescent males from the Gulf of St. Lawrence have been found to mate with pubescent-primparous females in the laboratory (Moriyasu and Conan ${ }^{6}$; SainteMarie and Lovrich, 1994; Sainte-Marie et al., 1997), but their reproductive contribution in the field was thought to be limited (SainteMarie et al., 1999; Sainte-Marie et al., 2008). Instead, small MM males were found to be the primary partners of pubescent-primiparous females (Sainte-Marie and Hazel, 1992). It is not known if MM males $<100 \mathrm{~mm} \mathrm{CW}$ in the eastern Bering Sea undergo seasonal migrations, but given their close proximity to primiparous females during summer (Figs. 5 and $7 \mathrm{C}$ ), they were the most readily available group of males to mate with these females.

Differences in the male-female mating dynamics of snow crabs from the eastern Bering Sea and those from eastern Canada are likely. Opportunities for different mating associations among the various reproductive stages (e.g., pubescent-primiparous and multiparous females and adolescent and MM males) could be greater in areas of steep bathymetry, for example, as a result of shorter migratory distances (Sainte-Marie et al., 2008) and related energetic costs (Foyle et al., 1989). The eastern Bering Sea shelf is flatter and wider than the Gulf of St. Lawrence. Because snow crabs are distributed along depth and temperature gradients according to their size and reproductive stage, the physical separation of these different groups may be greater over the eastern Bering Sea shelf than over the Gulf of St. Lawrence. Despite the geo-

\footnotetext{
${ }^{6}$ Moriyasu, M., and G. Y. Conan. 1988. Aquarium observation on mating behavior of snow crab, Chionoecetes opilio. ICES Council Meeting (C.M.) Documents 1986/K:9, 21 p. [Available at website.]
}

\section{Figure 7 legend cont.}

of adolescent males are classified by (E) small (70-100 $\mathrm{mm} \mathrm{CW})$ and (F) large (>100 mm CW) size classes. Relative abundance at each station was quantified as the proportion of MM males at each station in relation to MM males summed over all stations for all years. Dot sizes represent the following proportion ranges from smallest to largest: <0.002; 0.002-0.004; 0.004-0.008; 0.008-0.020; $>0.020$. Values of $\Sigma_{\mathrm{ij}} N_{\mathrm{ij}}$ are the sum of males captured at all stations $i$ for all years $j$. The black line indicates the $100-\mathrm{m}$ bottom-depth contour. 
graphic differences, however, migration habits among large MM males in the 2 regions appear to be quite similar. In both locations, large MM males migrate to deeper water after their terminal molts (Ernst et al., 2005), make limited seasonal migrations back inshore, overlap the distribution of mature multiparous females during the spring mating season, and exhibit size dependence in regard to migration distance.

Assuming that large MM males seasonally migrate for the purpose of mating, we believe the extent and timing of their migrations is likely to depend on both the distribution of mature females and the seasonal timing of their reproductive cycle. Snow crab distributions have been shown to contract northward after years of warmer bottom temperatures (e.g., 1975-1979; Orensanz et al., 2004), and to shift back to the south (Turnock and Rugolo ${ }^{4}$ ) after a series of more recent colder-than-average years (2007-2010) and more extensive cold pools (Stabeno et al., 2012). The tagged MM males in this study were, therefore, at liberty during a relatively cold period. As indicated in this study, multiparous females were in close proximity to the tagged males, but perhaps, when waters are warmer, a shift in male and female distributions may necessitate longer migrations for mating. Colder temperatures also delay seasonal embryo hatching (Moriyasu and Lanteigne, 1998; Webb et al., 2007) and consequently subsequent mating, and therefore may result in earlier occurrence of migrations during warmer years.

Although the tagging data indicate timed migrations across depth gradients, and therefore inshore and offshore movements, we could not resolve movements that may have occurred along depth isobaths and therefore could not describe distinct migration routes for individuals. Another limitation of our study is that, although data from the NMFS bottom trawl surveys provided a clear pattern for the summer distribution of mature females, we did not have similar information collected during the mating period. Similarly, the distributional data for small MM males was limited to summer samples, and their overlap (or lack of) with tagged males during other seasons could not be determined. Additionally, although broad-scale distributional differences were found among adolescent and MM males of different size classes and with different shell conditions, annual differences in their distributions could not be determined because of a lack of annual $\mathrm{CH}-\mathrm{CW}$ data needed to differentiate between adolescent and MM males. This shortcoming highlights the need for more comprehensive annual $\mathrm{CH}-\mathrm{CW}$ collections.

Because of the lack of a substantial inshore migration of large MM males, it is important to recognize the component of the population targeted by the fishery and the impact of the fishery on female mating dynamics and reproductive success. Because large commercial-size MM males remain on the outer shelf, the existence of a summer-winter spatial difference among large males (including adolescents) on the outer shelf must, in part, be due to the annual removal of MM males by the fishery. The highest concentrations of commercial-size males observed during the NMFS summer bottom trawl survey in 2010 were found near the Pribilof Islands on the middle shelf (Turnock and Rugolo ${ }^{4}$ ), but our tag recoveries do not indicate that this finding is a result of migration of commercial-size MM males. Instead, these males must have been recently terminally molted MM males (i.e., new shell males) that had yet to migrate offshore, as well as adolescents. Again, considering what appears to be low relative abundance of large MM males on the outer shelf during summer, there must be some level of large MM male depletion during winter, and the winter fishery must be largely dependent on the annual recruitment of these new-shell MM males to the outer shelf.

Because of significant removals of commercial-size MM males by the fishery on the outer shelf, female spawners could become more reliant on either small MM males or adolescent males for mating (see Ennis et al., 1990). As stated earlier, because pubescentprimiparous females reside on the middle shelf, they are likely to mate with small resident MM males. For multiparous females, which reside on the outer shelf, their likely mates are the large MM males targeted by the fishery. However, because the fishery in the eastern Bering Sea typically occurs from January through March, just before multiparous mating ( March-July), the capture of large MM males would exclude them from multiparous mating. Considering that recently terminally molted males cannot mate for perhaps 3 months (Conan and Comeau, 1986; Paul et al., 1995; Sainte-Marie et al., 1999), even those large recently molted males that survive the fishery may not contribute to multiparous mating that year.

Of concern here, other than the reliance of the fishery on only one pseudocohort (individuals that terminally molted in the same year; see Ernst et al., 2005), is whether the male sperm contribution to spawning is sufficient in terms of both quantity and quality. Are the numbers of mature males that remain after fishery harvesting abundant enough to provide the sperm reserves necessary for healthy clutch fertilization and subsequent robust populations? Preliminary research on spermathecal loads among primiparous and multiparous females in the eastern Bering Sea has shown that they were significantly lower than those of females in the Gulf of St. Lawrence (Rugolo et al. ${ }^{1}$; Slater et al., 2010). Although there was no evidence of sperm limitation within the eastern Bering Sea stock, there is still a concern that the stock could be vulnerable to recruitment overfishing that results from reliance on a male-only fishery. The question remains, do multiparous females then become more reliant on stored sperm from pubescent-primiparous mating that occurred before their own offshore migration, or do they become more reliant on sperm from small, noncommercial-size MM males (e.g., Ennis et al., 1988; 1990) and potentially bias the genetic pool 
toward smaller terminal sizes (Elner and Beninger, 1995; Tamone et al., 2005; Sainte-Marie et al., 2008)? Reduced reproductive output from multiparous females could place greater reliance upon mating and spawning of pubescent-primiparous females, which are known to have a lower fecundity (Haynes, et al., 1976; Sainte-Marie, 1993). Because multiparous mating is important for long-term sustainability of the snow crab in the eastern Bering Sea, it is important to ensure that adequate numbers of large MM males survive each year.

\section{Acknowledgments}

D. Pengilly provided the impetus for the research. R. Alinsunurin, J. Conner, and C. Armistead contributed to the tagging process and data acquisition. Reviews from L. Rugolo, J. Turnock, J. Webb, and 2 anonymous scientists significantly improved this manuscript. S. Hughes and the Bering Sea Fisheries Research Foundation (BSFRF) secured the vessels used for tagging. We are very grateful to skippers M. Wilson and J. Hochstein and to the crews of the FV Kiska Sea and FV Pacific Sun. We also acknowledge the staff of the NMFS Shellfish Assessment Program in Kodiak, Alas$\mathrm{ka}$, for the collection of data, upon which the presented distributions of snow crabs in the eastern Being Sea are based. This research was supported by the BSFRF, the National Cooperative Research Program (NOAA/ NMFS), and the Marine Conservation Alliance.

\section{Literature cited}

Bowers, F. R., M. Schwenzfeier, K. Herring, M. Salmon, J. Shaishnikoff, H. Fitch, J. Alas, and B. Baechler.

2011. Annual management report for the commercial and subsistence shellfish fisheries of the Aleutian Islands, Bering Sea and the westward region's shellfish observer program, 2009/10. Alaska Dep. Fish Game, Fish. Manage. Rep. 11-05, 254 p. [Available at website.]

Chilton, E. A., C. E. Armistead, and R. J. Foy.

2011. The 2010 eastern Bering Sea continental shelf bottom trawl survey: Results for commercial crab species. NOAA Tech. Memo. NMFS-AFSC-216, 139 p.

Conan, G. Y., and M. Comeau.

1986. Functional maturity and terminal molt of male snow crab, Chionoecetes opilio. Can. J. Fish. Aquat. Sci. 43:1710-1719. Article

Comeau, M., and G. Y. Conan,

1992. Morphometry and gonad maturity of male snow crab, Chionoecetes opilio. Can. J. Fish. Aquat. Sci. 49:2460-2468. Article

Comeau, M., G. Robichaud, M. Starr, J.-C. Therriault, and G. Y. Conan.

1998. Mating of snow crab Chionoecetes opilio (O. Fabricius, 1788) (Decapoda, Majidae) in the fjord of Bonne Bay, Newfoundland. Crustaceana 71:925-941. Article

Comeau, M., G. Y. Conan, G. Robichaud, and A. Jones.

1991. Life history patterns and population fluctuations of snow crab (Chionoecetes opilio) in the fjord of Bonne
Bay on the west coast of Newfoundland, Canada - from 1983 to 1990. Can. Tech. Rep. Fish. Aquat. Sci. 1817, $73 \mathrm{p}$.

Elner, R. W., and P. G. Beninger.

1995. Multiple reproductive strategies in snow crab, Chionoecetes opilio: physiological pathways and behavioral plasticity. J. Exp. Mar. Biol. Ecol. 193:93-112. Article

Ennis, G. P., R. G. Hooper, and D. M. Taylor.

1988. Functional maturity in small male snow crabs (Chionoecetes opilio). Can. J. Fish. Aquat. Sci. 45:2106-2109. Article

1990. Changes in the composition of snow crab (Chionoecetes opilio) participating in the annual breeding migration in Bonne Bay, Newfoundland. Can. J. Fish. Aquat. Sci. 47:2242-2249. Article

Ernst, B., J. M. Orensanz, and D. A. Armstrong.

2005. Spatial dynamics of female snow crab (Chionoecetes opilio) in the eastern Bering Sea. Can. J. Fish. Aquat. Sci. 62:250-268. Article

Foy, R. J., and C. E. Armistead.

2013. The 2012 eastern Bering Sea continental shelf bottom trawl survey: results for commercial crab species. NOAA Tech. Memo. NMFS-AFSC-242, 147 p.

Foyle, T. P., R. K. O'Dor, and R. W. Elner.

1989. Energetically defining the thermal limits of the snow crab. J. Exp. Biol. 145:371-393.

Gutierrez, A.

2012. Opilio catch picks up just in time for a fast finish. Pacific Fish. 33:22.

Gravel, K. A., L. J. Watson, D. Pengilly.

2006. The 2005 eastern Bering Sea snow crab Chioecetes opilio tagging study. Alaska Dep. Fish Game, Fish. Manage. Rep. 06-31, 41 p. [Available at website.]

Haynes, E., J. F. Karinen, J. Watson, and D. J. Hopson.

1976. Relation of number of eggs and egg length to carapace width in the brachyuran crabs Chionoecetes bairdi and $C$. opilio from the southeastern Bering Sea and C. opilio from the Gulf of St. Lawrence. J. Fish. Res. Board Can. 33:2592-2595. Article

Hooper, R. G.

1986. A spring breeding migration of the snow crab, Chionoecetes opilio (O. Fabr.), into shallow water in Newfoundland. Crustaceana 50:257-264. Article

Kotwicki, S., and R. R. Lauth.

2013. Detecting temporal trends and environmentallydriven changes in the spatial distribution of bottom fishes and crabs on the eastern Bering Sea shelf. Deep Sea Res. (II Top. Stud. Oceanogr.) 94:231-243. Article

Kruse, G. H., A. V. Tyler, B. Sainte-Marie, and D. Pengilly.

2007. A workshop on mechanisms affecting year-class strength formation in snow crabs (Chionoecetes opilio) in the eastern Bering Sea. Alaska Fish. Res. Bull. 12:278-291. [Available at website.]

Lauth, R. R.

2011. Results of the 2010 eastern and northern Bering Sea continental shelf bottom trawl survey of groundfish and invertebrate fauna. NOAA Tech. Memo. NMFSAFSC-227, $256 \mathrm{p}$.

Lauth, R. R., and D. G. Nichol.

2013. Results of the 2012 eastern Bering Sea continental shelf bottom trawl survey of groundfish and invertebrate resources. NOAA Tech. Memo. NMFS-AFSC-256, $162 \mathrm{p}$. 
Lovrich, G. A., B. Sainte-Marie, and B. D. Smith. 1995. Depth distribution and seasonal movements of Chionoecetes opilio (Brachyura: Majidae) in Baie Sainte-Marguerite, Gulf of Saint Lawrence. Can. J. Zool. 73:1712-1726. Article

Moriyasu, M. and M. Comeau.

1996. Grasping behavior of male snow crab Chionoecetes opilio (O. Fabricius, 1788) (Decapoda, Majidae). Crustaceana 69:211-222. Article

Moriyasu, M. and C. Lanteigne.

1998. Embryo development and reproductive cycle in the snow crab, Chionoecetes opilio (Crustacea:Majidae), in the southern Gulf of St. Lawrence, Canada. Can. J. Zool. 76:2040-2048. Article

Orensanz, J., B. Ernst, D. A. Armstrong, P. Stabeno, and P. Livingston.

2004. Contraction of the geographic range of distribution of snow crab (Chionoecetes opilio) in the eastern Bering Sea: an environmental ratchet? CalCOFI Rep. 45:65-79. [Available at website.]

Otto, R. S.

1998. Assessment of the eastern Bering Sea snow crab, Chionoecetes opilio, stock under the terminal molt hypothesis. In Proceedings of the North Pacific Symposium on Invertebrate Stock Assessment and Management (G. S. Jamieson and A. Campbell, eds.), p. 109124. Can. Spec. Publ. Fish. Aquat. Sci. 125.

Parada, C., D. A. Armstrong, B. Ernst, S. Hinkley, and J. M. Orensanz.

2010. Spatial dynamics of snow crab in the eastern Bering Sea-putting together the pieces of the puzzle. Bull. Mar. Sci. 86:413-437.

Paul, A. J., J. M. Paul, and W. E. Donaldson.

1995. Shell condition and breeding success in Tanner crabs. J. Crust. Biol. 15:476-480. [Available at website.]

Sainte-Marie, B.

1993. Reproductive cycle and fecundity of primiparous and multiparous female snow crab, Chionoecetes opilio, in the northwest Gulf of Saint Lawrence. Can. J. Fish. Aquat. Sci. 50:2147-2156. Article

Sainte-Marie, B., T. Gosselin, J.-M. Sévigny, and N. Urbani.

2008. The snow crab mating system: opportunity for natural and unnatural selection in a changing environment. Bull. Mar. Sci. 83:131-161.

Sainte-Marie, B. and F. Hazel.

1992. Moulting and mating of snow crabs, Chionoecetes opilio (O. Fabricius), in shallow waters of the northwestern Gulf of Saint Lawrence. Can. J. Fish. Aquat. Sci. 49:1282-1293. Article

Sainte-Marie, B., and G. A. Lovrich.

1994. Delivery and storage of sperm at first mating of female Chionoecetes opilio (Brachyura: Majidae) in relation to size and morphometric maturity of male parent. J. Crust. Biol. 14:508-521. [Available at website.]

Sainte-Marie, B., and C. Carrière.

1995. Fertilization of the second clutch of eggs of snow crab, Chionoecetes opilio, from females mated once or twice after molt to maturity. Fish. Bull. 93:759-764.

Sainte-Marie, B., J.-M. Sévigny, and Y. Gauthier.

1997. Laboratory behavior of adolescent and adult males of the snow crab (Chionoecetes opilio) (Brachyura: Majidae) mated noncompetitively and competitively with primiparous females. Can. J. Fish. Aquat. Sci. 54:239-248. Article
Sainte-Marie, N. Urbani, J.-M. Sévigny, F. Hazel, and U. Kuhnlein.

1999. Multiple choice criteria and the dynamics of assortative mating during the first breeding season of female snow crab Chionoecetes opilio (Brachyura, Majidae). Mar. Ecol. Prog. Ser. 181:141-153. Article

Slater, L. M., K. A. MacTavish, and D. Pengilly.

2010. Preliminary analysis of spermathecal load of primiparous snow crab (Chionoecetes opilio) from the eastern Bering Sea, 2005-2008. In Biology and management of exploited crab populations under climate change: $25^{\text {th }}$ Lowell Wakefield Fisheries Symposium; Anchorage, AK, 10-13 March 2009 (G. H. Kruse, G. L. Eckert, R. J. Foy, R. N. Lipcius, B. Sainte-Marie, D. L. Stram, and D. Woodby, eds.), p. 237-247. Univ. Alaska Fairbanks, Alaska Sea Grant College Program Rep. AK-SG-10-01. Article

Somerton, D. A.

1981. Life history and population dynamics of two species of Tanner crab, Chionoecetes bairdi and C. opilio, in the eastern Bering Sea with implications for management of the commercial harvest. Ph.D. diss., 220 p. Univ. Wash., Seattle.

1982. Bipartite breeding: a hypothesis of the reproductive pattern in Tanner crabs. In Proceedings of the international symposium on the genus Chionoecetes; Anchorage, AK, 3-6 May (B. Melteff, ed.), p. 283289. Univ. Alaska Fairbanks, Alaska Sea Grant Rep. AK-SG-82-10.

Stabeno, P. J., N. B. Kachel, S. E. Moore, J. M. Napp, M. Sigler, A. Yamaguchi, and A. N. Zerbini.

2012. Comparison of warm and cold years on the southeastern Bering Sea shelf and some implications for the ecosystem. Deep Sea Res. (II Top. Stud. Oceanogr.) 65:31-45. Article

Stevens, B. G., W. E. Donaldson, J. A. Haaga, and J. E. Munk. 1993. Morphometry and maturity of paired Tanner crab, Chionoecetes bairdi, from shallow- and deepwater environments. Can. J. Fish. Aquat. Sci. 50:1504-1516. Article

Tamone, S. L., M. M. Adams, and J. M. Dutton.

2005. Effect of eyestalk-ablation on circulating ecdysteroids in hemolymph of snow crabs, Chionoecetes opilio: physiological evidence for a terminal molt. Integr. Comp. Biol. 45:166-171. Article

Tamone, S. L., S. J. Taggart, A. G. Andrews, J. Mondragon, and J. K. Nielsen.

2007. The relationship between circulating ecdysteroids and chela allometry in male Tanner crabs: evidence for a terminal molt in the genus Chionoecetes. J. Crust. Biol. 27:635-642. [Available at website.]

Taylor, D. M., R. G. Hooper, and G. P. Ennis.

1985. Biological aspects of the spring breeding migration of snow crabs, Chionoecetes opilio, in Bonne Bay, Newfoundland (Canada). Fish. Bull. 83:707-711.

Webb, J., and J. Bednarski.

2010. Variability in reproductive potential among exploited stocks of Tanner crab (Chionoecetes bairdi) in southeast Alaska. In Biology and management of exploited crab populations under climate change: $25^{\text {th }}$ Lowell Wakefield Fisheries Symposium; Anchorage, AK, 10-13 March 2009 (G. H. Kruse, G. L. Eckert, R. J. Foy, R. N. Lipcius, B. Sainte-Marie, D. L. Stram, and D. Woodby, eds.), p. 295-317. Univ. Alaska Fairbanks, Alaska Sea Grant College Program Rep. 10-01. Article 
Webb, J. B., G. L. Eckert, T. C. Shirley, and S. L. Tamone. 2007. Changes in embryonic development and hatching in Chionoecetes opilio (snow crab) with variation in incubation temperature. Biol. Bull. 213:67-75.

Zheng, J., G. H. Kruse, and D. R. Ackley.

2001. Spatial distribution and recruitment patterns of snow crabs in the eastern Bering Sea. In Spatial processes and management of marine populations (G. H. Kruse, N. Bez, A. Booth, M. W. Dorn, S. Hills, R. N. Lipcius, D. Pelletier, C. Roy, S. J. Smith, and D.Witherell, eds.), p. 233-255. Univ. Alaska Fairbanks, Alaska Sea Grant College Program AK-SG-01-02. Article 